\title{
The indeterminacy of sensual expressiveness and the fluidity of mindfulness
}

\begin{abstract}
Although sensual curriculum would open up new horizons different from textual curriculum, they both can get entangled within the tyranny of mindlessness and impede the process of creativity. The paper discusses how Langerian Mindfulness and with its mindful driven sensual curriculum can transcend common forms of sensibility and bring about exquisite and novel modes of expressiveness.
\end{abstract}

Keywords: mindfulness, expressiveness, mindlessness, mindful oriented curriculum
Volume I Issue 7 - 2014

Sayyed Mohsen Fatemi

Department of Psychology, Harvard University, USA

Correspondence: Sayyed Mohsen Fatemi, Department of Psychology, Harvard University, 33 Kirkland Street,WJH 232, Cambridge, MA 02138, USA, Tel 617-3099124,

Emailsmfatemi@wjh.harvard.edu

Received: July II, 2014 | Published: November 26, 2014

\section{Introduction}

Approaches on senses and sensing within education have been mainly inspired and affected by psychological perspectives where the initial focus has discussed the stimulation of receptor cells and the process of information transmission to the brain centers. The presentations of the absolute threshold and the difference threshold within neurophysiological and psychological research and their implications have examined how the amount of stimulation may have an influence on the psychological experience of the stimuli.

The discussions have concentrated on the pathways between the five senses namely vision, hearing, smell, touch and taste and the specific areas on the brain. Accordingly seeing a flower in the garden, for example, can be attributed to the electrical activation of the primary visual cortex in the occipital lobes of the brain as the hearing sensation may be ascribed to the activation of the auditory complex in the temporal lobes. Meanings to the sensations have, of course, been discussed in the framework of perceptions where interpretations of the experience have come distinct from the mere process of sensation.

The configuration of psychological research on sensation and perception and their discussion of senses seem to have been implicitly embedded within a look into the past: the prior knowledge, the schema, the accessibility to previous exposure, the search for a repertoire that must have been already established.

Deregowski, et.al, ${ }^{1}$ for instance, demonstrated that how the sense of vision and the perception of pictures need to be related to the people's past educational and socialization experiences. The people of Mekan in Ethiopia who seemingly had no previous education and had not been exposed to pictures could hardly identify the picture of animals that were presented to them. In a more recent example, Sporer et.al., ${ }^{2}$ indicated that Turkish-born children in Europe were faster than the Austrian children in matching the faces of Turkish people. The research displayed no difference in perception when it came to the matching of German faces. Both groups namely Turkish and Austrian matched the German faces equally fast.

Emergence of priming, mapping, cognitive models, assimilation, accommodation, and such like past stricken concepts within learning strategies and pedagogical approaches may justify the attempt for providing a structured educational framework where sensibility of senses needs to be determined on the strength of their proximity and adjacency to the established curriculum. In other words, established curriculum would propound a fairly stable agenda for learning and teaching, curriculum planning and policy making and would have a rather stringent emphasis on abiding by the pre-identified ways of learning. This has had huge implications for the sensibility of senses in the world of education. Apart from the monolithic perspective of some educators in ostracizing the application of senses without a direct linkage to the prescribed text, some others have been mainly enmeshed within the application of senses with a focus on the past. This, albeit fruitful and helpful, in expressing the personally lived experiences, has reinforced the tendency of the sensibility of senses within the paradigmatic analysis of the past.

Students may be encouraged in classes to be well attuned to their senses and be willing and prepared to express and create avenues through which the content of particular senses manifests themselves. While this notion of sense expressiveness and its experiential sedimentation would help the learners be more effectively in touch with their own positions and experience more empowerment, yet it could go one sided if it cannot generate novel and innovate forms of expressiveness. A past based sensual mode of expressiveness would be ultimately bound by the same textual determinacy.

In questioning the determinacy of the established curriculum, Langer ${ }^{3}$ writes:

From time to time educators attempt to recognize the fluidity of knowledge by providing students with a list of the pros and cons of a particular idea or theory. Much as a physician might list the potential negative side effects along with the expected benefits of a treatment, critical thinking is sometimes taught in schools by having students list the advantages and disadvantages of a controversial idea. Such an exercise almost invariably falls short of the recognition that each potential benefit may also be a liability and that a disadvantage may become an advantage.

The determinacy of the established curriculum and its plausibility has its roots in the etiological goal of education as the hegemony and mastery. Deep inside the concept of the very mastery, there lies an urge for certainty which is seemingly unfolding itself in the process of knowing. The past stricken education would entangle the senses within the same incarceration and would lead them through the trail of the past seeking predisposition to gain sensibility. On challenging the domineering implications of intelligence, Langer ${ }^{3}$ who argues that most of our learning takes place mindlessly indicate that. 
Although the proliferation of dimensions of intelligence may help prop up students' sense of self-worth, in the process of indentifying strengths as may be unintentionally undermining students' development. Not only do students who are helped lost the potential benefit of generating a view of their own abilities, but the recipients of most remedial efforts usually accept a devaluation of self. Such devaluation sometimes causes people to compensate by devaluating others. In other words, people accept the ways others have been shown to be better than they by identifying ways in which they are better than others. Adding dimensions of intelligence encourages such labeling and competition.

Curriculum as established in its western framework is inextricably tied to the scientific rigor of the natural sciences and its implications for human and social sciences. Deep down the prescribed methods and approaches within curriculum as planned, there lies the idea of a scientific truth that need to be promoted. The modes of expressiveness, thus, need to gain their sensibility within the pre-established paradigms. The emphasis, again, is on the structured, organized, and composed models from the past; the tendency to look for the fit between what is and the schema of the scientific models.

Challenging the hegemony of the scientific model as the deciding factor in our modes of living and being, Spariosou ${ }^{4}$ writes:

We might posses "the best" scientific theory, such as deep ecology, the "best" information and communication technology, such as digital and quantum computers, or the "best" political system, such as democracy. And yet, we may end up putting them all to inappropriate and counterproductive uses, as we have seen happen repeatedly throughout the history of scientific and technological development, as well as the history of world politics.

When sensibility is quested in the abode of the established structures and models as defined by scienticism, there would be an attempt to compare the expressed ways of the community of learners with the plausible modes of correspondence within the structural schema of the past: it should fit the big Text of expressiveness to make sense. Therefore, you may see the ineluctable manifestation of an approach towards what has already been established. Teachers preoccupation, moving in line with the established curriculum, would, thus, be a concern about their match with the pre-organized system of schemas and scripts. Cognition is more concentrated on factors that induce the compatibility with the pre-existing models. The modes of expressiveness, albeit creative, are necessarily promoted with a tilt towards the hegemony of the schemas of the past.

Teachers who embrace the curriculum as established paradigm as the leading factor in their pedagogical approaches would end up "stuffing" learners with numerous forms of mapping that are inextricably connected to the hegemony of the past. The assumptions here indicate that there is a text that needs to be abided by, that needs to be implemented, and that needs to serve as the illuminating source for action. The Text in the curriculum as established eschews from fluidity and transformation since any change in the structural patterns of the leading Text would contradict the implementation and application of the Text. The outcry for being scientific unfolds itself within the underlying excavation of the curricular endeavors.

Questioning the hegemony of this indulgence in the scientific infatuation, Gardner ${ }^{5}$ indicates:

What sense would we make of the greatest work of art or literature, or the most important religious or political ideas, or the most enduring puzzles about the meaning of life and death, if we only thought of them in the manner of a scientific study or proof? If all we did was quantify? What political or business leader would be credible, at the time of crisis, if all he could do was offer scientific explanations or mathematical proofs, if he could not address the hearts of his audience? The great physicist Niels Bohr once mused on this irony: "there are two kinds of truth, deep truth and shallow truth, and the function of Science is to eliminate the deep truth.".

Notwithstanding the fruitful applicability of the schematic structures associated with the scientific rigor for curriculum planning and educational policy making, the language of the past stricken pedagogy delineates attempts that contain modes of expressiveness. Sensual modes of expressiveness would, therefore, fall into two categories: the past based sensual modes of expressiveness where the expressiveness is placed in a connectedness to the schematic structures of the pre-established models. This way, the senses namely vision, hearing, smell, touch and taste can have their own modes of expressiveness with their educational implications. Nonetheless, they need to pass through the filters with a conspicuous reliance on the pre-established schematic structures. The learners, albeit active in this mode of expressiveness, would largely depend on reference points that define sensibility of sensual expressiveness by virtue of the flux of the previously made structures. In other words, sensual curriculum can turn out to be in the language of Langer ${ }^{6}$ mindlessness that is operating from a single perspective enmeshed in "the premature cognitive commitment" of the past. Mindlessness based sensual curriculum, although uses senses and their plethora of benefits in its programs, would suggest a monolithic perspective that ultimately seek the connectedness to the schematic structures of the past as the criteria for viability and reliability. This would have huge implications for learners as it engages the community of learners into delving into the pre-identified windows of knowing. As the avenues of knowing and understanding are contained more in the pre-identified chapters of schematic analysis of the past, they tend to dictate what to think and how to think in accordance with the syntagmatic analysis of the hegemony of the previously acquired modes of expressiveness. There would hardly be novelty, creativity and innovation in a trail where the repetition of the frequently appeared schemas prescribe certain plausible modes of thinking and expressiveness. The text created by mindless based sensual curriculum may be distinct from the text created by the pervasive non-sensual curriculum; yet, they would limit the possibilities and circumscribe the horizons of expressiveness as they merely substantiate themselves through the past stricken approach of sensibility.

The mindlessness curriculum based modes of expressiveness would move in the framework of a reductionism which seems to be the corollary of the scientific infatuation. Hence, the sensual modes of expressiveness which is placed on the horizons of the very reductionism would deprive the educator and the leaner of experiencing the novelty of the unexpressed.

Ricoeur $^{7-8}$ maintains that "in scientific language there is an attempt to reduce as much as possible this polysemy, this plurivocity to univocity: one word-one sense." He points out that "it is the task of poetry to make words mean as much as they can and not as little as they can. Therefore, not to elude or exclude this plurivocity, but to cultivate it, to make it meaningful, powerful, and therefore to bring back to language all its capacity of meaningfulness."

To understand the creation of possibilities through the act of poetry, one needs to disengage himself/herself from what Langer ${ }^{3}$ calls "premature cognitive commitment." A poetic based curriculum 
would open up the possibilities for new modes of expressiveness since sensibility is no longer in effect through the previously made schematic analysis. This requires a preparation to be in Langerian term ${ }^{6}$ "mindful." This mindfulness, in Langerian terms, requires noticing new things, paying attention to a flux distinct from the past, exploring the layers of the unexpressed. The essence of Langerian mindfulness occurs in engagement. Being engaged constitutes one of the main components of mindfulness. As the person mindfully gets engaged in the process of experiencing the experience, he/she is not only there but also he/she is being there. The engagement gives rise to living in the moment in a mindful manner. In mindless education, students and teachers are not living in the moment. Their working memory keeps them in the established categories. Once one is locked in information, he/she is not looking for alternative ways of looking at the subject of the study. This may help us understand how in mindlessness based education propositions are considered absolute whereas in a mindfulness based education the statements and propositions are presented in conditional format. The conditional formatting would allow the learner understand the tentativeness of the proposition and thus would help him to look into other possibilities. As the textual based curriculum can be entrapped in the subjugation of mindlessness, the same can happen for the sensual based curriculum. In other words, the sensual modes of expressiveness may be afflicted with the sovereignty of the past stricken identification.

In textual based curriculum, the teacher is merely outcome oriented: it is just important that the student would produce the desired outcome. In a mindful based education, however, the teacher pays attention to both process and the outcome. Learning becomes important as the student takes the pen to write. The whole process is of great merit. Let's look at the following from Dostoevsky's novel, The Double where it is shown how human expressiveness can be inventive despite the objective limits and codes which govern it, to display and reveal the potentiality of diversity of language, the diversity and potentiality that every day ordinary discourse unflinchingly and relentlessly extinguishes and erodes. The example may demonstrate the dialectics of the expressed and the unexpressed within a mindless or a mindful reference point.

The low-ranking clerk Golyadkin, in Dostoevsky's novel, hires a magnificent carriage to take him down the Nevsky Prospeckt. He wishes to impress. But suddenly another carriage pulls up alongside his. Inside it sits not a woman to be seduced, but his superior Andrei Filipovich to be obeyed. No place to hide. Caught where he should not be. The other had come too close. Eventually Golyadkin was to go mad: "Should I bow or shouldn't I? Should I acknowledge him? Admit that it is me? Or should I pretend I'm someone else, someone strikingly resembling me, and look completely different?" Golyadkin asked himself in indescribable anguish. "Yes that's it: I'm not me and that's all there is to it." So he thought, his eye fixed on Andrei Filipovich as he took off his hat to him. "I, I, I. . . no, nothing, sir," he stammered in a whisper. "The fact is, it's not me ... . Yes, that's all there is to it."

The mindless based textual or sensual curriculum would suggest modes of sensibility on the strength of a relationship seeking to the previously created compartmentalization. That suggests that the tension of the entrapment within the schematic analysis of the past would impede the process of noticing new things that have no room in the sensibility of the pre-established paradigms.

Shotter ${ }^{9}$ explains this well by saying:
"In fulfilling our responsibilities as competent and professional academics, we must write systematic texts; we run the risk of being accounted incompetent if we do not. Until recently, we have taken such texts for granted as a neutral means to use how we please. This, I now want to claim, is a mistake, and now we must study their influence."

Both the textual and sensual curriculum which operates in mindlessness is built by virtue of the certainty of knowing. This certainty that has its discursive epistemological and ontological roots maintained in a positivist discourse of psychology looks for stability of the modes of expressiveness with a reference to the sensibly acquired patterns. The emphasis, here again, is a highlight of the identified categories.

In a revolutionary perspective on our modes of thinking and expressiveness, Langer ${ }^{10}$ propounds that moving from a position of not knowing would provide us with the panacea of more possibilities to express the unexpressed: it allows us to go beyond the preestablished discourses of thinking and it promotes paying attention to novel things.

Explaining this in the context of learning and education, Langer ${ }^{10}$ writes:

When we learn mindlessly, we look at experience and impose a contingent relationship between two things-what we or someone else did and what we think happened as a result. We interpret that experience from a single perspective, oblivious to the other ways it can be seen. Mindful learning looks at experience and understands that it can be seen in countless ways, that new information is always available, and that more than one perspective is both possible and extremely valuable. It's an approach that leads us to be careful about what we "know" to be true and how we learn it. At the level of the particular experience, each event is unique.

Deep down the position of knowing as the leading factor of the mindlessly based curriculum, the notion of certainty unfolds itself. The textual and sensual curriculum would be both abortive as long as they linger in the stability of the mindlessly repeated schematic analysis. The learners, in both cases, would express themselves in line with a series of repetition, organization and structures that resonate with the pre-existing patterns.

Challenging this position of certitude and certainty and calling for the fluidity of living in the moment through observing new things, Langer ${ }^{10}$ writes:

Certainty is a cruel mindset. It hardens our minds against possibility and closes them to the world we actually live in. When all is certain, there are no choices for us. If there is no doubt, there is no choice. When we are certain, we are blind to the uncertainties of the world whether we recognize it or not. It is uncertainty that we need to embrace.

The mindful based sensual curriculum is distinguished from the mindless based sensual curriculum in that it openly creates possibilities and avidly looks for newness within the modes of expressiveness and the things of the expressed. The art based curriculum which may be the translation of one form of sensual expressiveness can also depart from mindlessness and proactively and mindfully create possibilities or can be plagued with the tyranny of the prescriptive modes of schematic analysis thus proceeding within the realm of mindlessness. The enhancement of possibilities in the heart of mindfulness would 
help the sensual expressiveness explore the realm of sensibility beyond the pre-determined scripts of certainty. This can facilitate the process of transcending the commonly accepted forms of sensation.

Jackson's description of class-room odors in an elementary school may indicate how an iota of mindfulness would reveal new angles of expressiveness that may have been long obscured by the mindless flow of the continuing scripts of life. In his description, Jackson ${ }^{11}$ states:

Schools may use different brands of wax and cleaning fluid, but they all seem to contain similar ingredients, a sort of universal smell which creates an aromatic background that permeates the entire building. Added to this, in each classroom, is the slightly acrid scent of chalk dust and the fain hint of fresh wood pencil shavings. In some rooms, especially at lunch time, there is the familiar odor of orange peels and peanut butter sandwiches, a blend that mingles in the late afternoon (following recess) with the delicate pungency of children's perspiration.

A mindful driven sensual curriculum, thus, makes an attempt at elucidating the infinite modes of expressiveness through inducing a proactively continuous fervor in noticing new things within the modes of expressiveness and the subjects of expressiveness. Creative expressivity and inventive expression of mindfulness would hardly be codified: we cannot limit the expressiveness and variety of thinking to several identified ways. The mindful driven sensual curriculum unfolds itself in the open understanding of happenings in an unrestrained manner. A mindful based sensual curriculum, would, allow the learners to munificently live in the moment through creating a comfort level where the observer does not see himself/herself bound by the tyranny of the cognitive mapping. This would have different implications for all senses. Along with a discernment of novelty in the moment, the learners experience a continuous flow of newness.

Imagine that you are passing by scenery where towering trees and plush greenness have brought an inexpressibly amazing spectacular panorama and as you lark along the rims of the path way, you also smell the redolence of a breeze gently rippling through everything under the shimmering sunlight and you also get saliently impressed by the imminently looming vista displaying an esoteric, arcane and recondite dispersion of an exclusively unique shade where the sunlight ceases to flaunt its piercing footprint: an ineffably bedazzling combination of the light with the smoothness of the shade under the trees where the genuflection of the trees' appendages have powerfully enriched the ornament colorfulness. There are different ways you can approach the described presence around you as you mindfully experience the sensual modes of expressiveness.
The fluidity of mindfulness would enrich the indeterminacy of sensual expressiveness and would promise the possibility of selfcreation through the expansion of choices. This would enlighten how the political, personal and cultural position of the person can be enlivened through a recondite discovery of the relationship between the modes of expressiveness and the search for new possibilities of exploration.

\section{Acknowledgments}

None.

\section{Conflicts of interest}

Author declares there are no conflicts of interest.

\section{Funding}

None.

\section{References}

1. Deregowski JB, Muldrow ES, Muldrow WF. Perceptual recognition in a remote Ethiopian population. Perception. 1972;1(4):417-425.

2. Sporer SL, Trinkl B, Guberova E.Matching faces: differences in processing speed of out-group faces by different groups. Journal of Cross-Cultural Psychology. 2007;38(4):398-412.

3. Langer EJ.Mindfulness. Reading, Addison-Wesley, MA. 1989.

4. Spariosu MI. Global intelligence and human development: Toward an Ecology of global learning. The MIT Press, Cambridge. 2004. p.296

5. Gardner H. Five minds for the future. Harvard Business School Press, Boston, USA. 2006. p. 369-373.

6. Langer EJ. The power of mindful learning. Reading, Addison Wesley, MA. 1997.

7. Ricoeur P. From text to action. Essays in hermeneutics. North Western University Press, Illinois, USA. 1991.

8. Ricoeur P. A Ricoeur Reader: Reflection and Imagination. University of Toronto Press, Toronto, Canada. 1991. p.531

9. Shotter J. Conversational realities. Sage Publication Ltd, London. 1993. p.208.

10. Langer E. Counter clock wise: mindful health and the power of possibility, Ballentine Books, New York, USA. 2009.

11. Jackson PW. Life in classrooms. Holt, Rinehart, \& Winston, New York, USA. 1968. 